\title{
Elementos "foráneos" en las necrópolis tardorromanas de Beiral (Ponte de Lima, Portugal) y Vigo (Pontevedra, España): de nuevo la cuestión del siglo V d. C. en la Península Ibérica*
}

\author{
Jorge López Quiroga** \\ (Universidad Autónoma de Madrid)
}

\begin{abstract}
Resumen
La cronología de todo el período denominado como "visigodo" se basa en los elementos de ajuar funerario de procedencia "foránea" hallados en diferentes necrópolis fechadas entre finales del siglo V y comienzos del VIII d. C. en el área central de la Península. No obstante, la presencia de materiales "foráneos" de comienzos y mediados del siglo $\checkmark \mathrm{d}$. C. en otros sectores geográficos de Hispania, plantea la necesidad de revisar la cronología y significación de estos ajuares para el conjunto de la Península. En este sentido, los elementos "foráneos" hallados en Beiral y en Vigo reabren el debate sobre esta cuestión y muestran la importancia de las conexiones entre la Península lbérica y el área danubiana.
\end{abstract}

\begin{abstract}
The chronology of the so-called "visigothic" period is based on burials of foreign origin founds in different graves dated between the end of the 5th century and beginnings of the 8th century in the central area of the Iberian Peninsula. However, we konw another foreign burials in other geographich sectors of Hispania dated in the first half of the 5th century. Then it's necessary to review the chronology and meaning of this burials for the whole Iberian Peninsula. In this sense, the foreign burials found in Beiral and Vigo have an special signification in this debate and also show the importance of the connections between the Iberian Peninsula and the danubiana area.
\end{abstract}

La cuestión de los hallazgos denominados como "germánicos" atribuibles al siglo V d. C. es, sin duda, uno de los problemas claves de la Arqueología del período de las "Grandes Migraciones" de los pueblos bárbaros en la Península Ibérica (König, 1980, 220-247; könig, 1981, 299-360; Ebel-Zepezauer, 1994, 380-397; Palol, 1991, 279-282; Schulze-Dörrlamm, 1986; Kazanski, 2000, 189-202). En efecto, la actual cronología correspondiente al conjunto del período visigodo se basa en los hallazgos de origen o procedencia "foránea" descubiertos en las necrópolis fechadas entre finales del siglo $\mathrm{V}$ y comienzos del VIII d. C. (Sasse, 1997, 29-48). En este sentido, una tabla cronológica con diferentes niveles ha sido elaborada por Gisella Ripoll (Ripoll, 1991, 111-132) (Fig. 1). Esta cronología

* Queremos agradecer desde aquí a la Profr ${ }^{\mathrm{a}}$. Dr ${ }^{\mathrm{a}}$. Raquel Casal su amabilidad en la cesión de las fotografías correspondientes al collar de Vigo, así como las valiosas informaciones que nos ha proporcionado sobre esta interesante necrópolis. relativa hace referencia a los objetos de adorno personal hallados en diferentes necrópolis del centro de la Península, en la meseta castellana, y comienza en el denominado "nivel II", es decir, hacia el 480/90 en el momento en que las fuentes mencionan el paso de los Visigodos a la Península Ibérica provenientes de Aquitania.

Esta tabla cronológica hace alusión, como es lógico, a materiales considerados como visigodos; sin embargo, resulta evidente, tanto a partir de las fuentes textuales como de las arqueológicas, la existencia de un "nivel I" entre 409/11, momento de la entrada de Vándalos, Suevos y Alanos, y el 480/90, cuando llegan los Visigodos (Fig. 1). Es decir, un "nivel I" que se correspondería con el "nivel D2 y D3" de la cronología establecida por Tejral para el centro y el este de

\footnotetext{
** Departamento de Prehistoria y Arqueología. Facultad de Filosofía y Letras. Universidad Autónoma de Madrid. e-mail: jorge.quiroga@uam.es/jorgequiroga@hotmail.es
} 


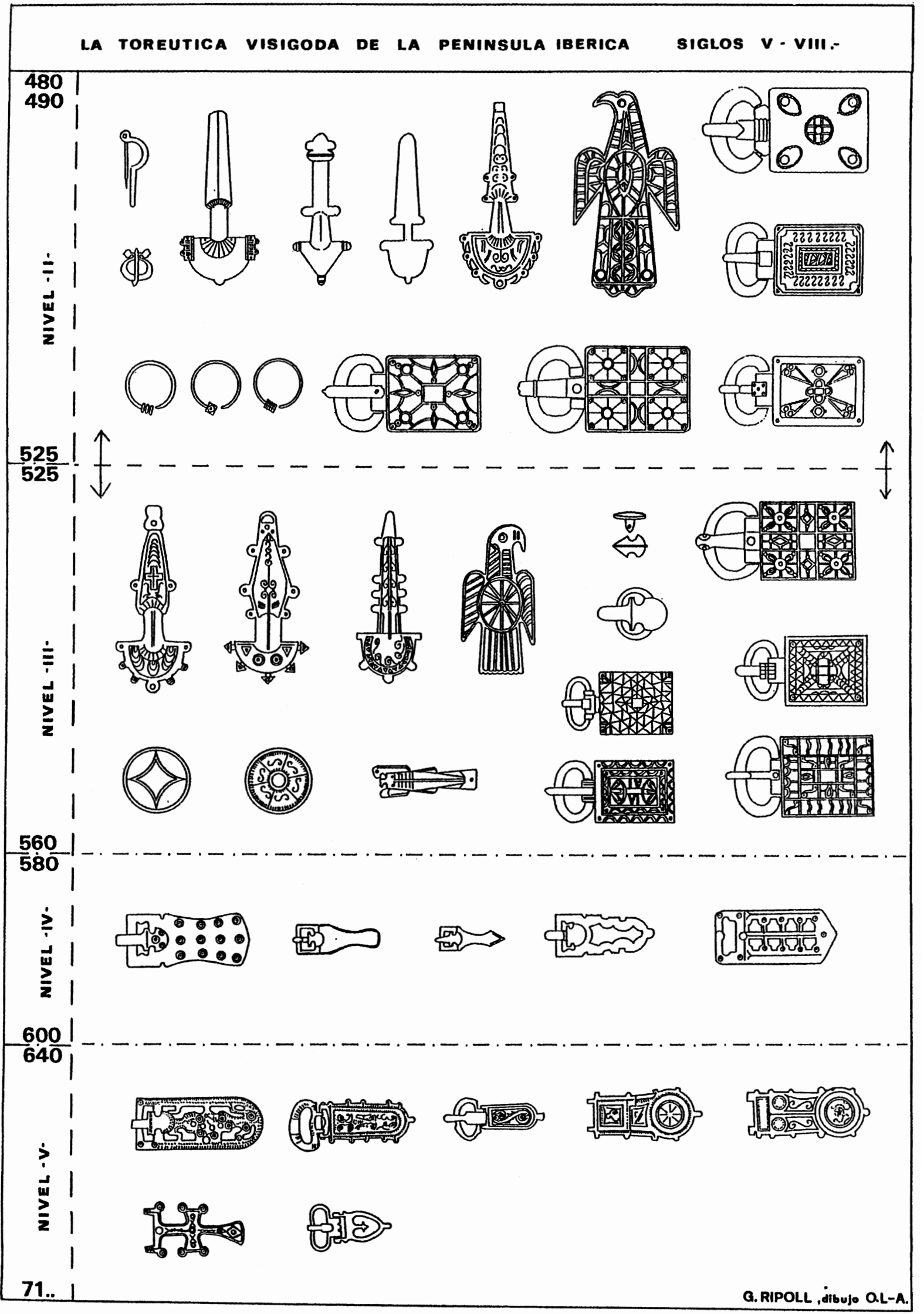

Figura 1.- Tabla tipo-cronológica de la toréutica de la Península Ibérica entre los siglos V-VIII, según G. Ripoll (tomado de Ripoll, G. "Materiales funerarios de la Hispania visigoda ...", art. cit., 120). 


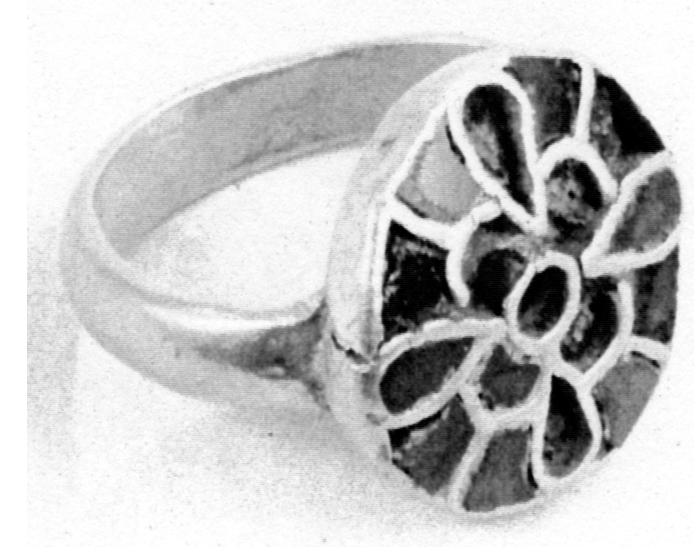

Figura 2 a.- Collar o diadema de oro hallado en la necrópolis de Beiral (Ponte de Lima, Portugal), $1^{a}{ }_{-}$del s. Vd. C. (fotografía tomada de Mattoso, J. História de Portugal. I. Antes de Portugal ed. Estampa, Lisboa, 341).

Europa ((Tejral, 1988, 223-304; Ibid., 1997, 321392; Ibid., 1999, 205-271).

Pensamos, además, que es perfectamente lícito hablar de "período de las migraciones de conjuntos populares" (Volkerwanderungszeit) en la Península Ibérica puesto que no sólo los Vándalos, los Suevos o los Alanos, sino otros grupos "germánicos" orientales y occidentales (y entre ellos, por supuesto, Visigodos y Ostrogodos) han llegado o se han instalado en Hispania en el curso del siglo V d. C. En efecto, se constata la llegada a la Península de un heterogéneo conjunto de colonos militares (Alanos, Vándalos, Cuados y Marcomanos provenientes de Panonia) a los que se debieron de añadir grupos de Alamanes pertenecientes a la antigua estirpe sueva. Todo este conjunto de gens se componía mayoritariamente de soldados, de colonos y letes con una conciencia étnica muy débil por no decir que casi inexistente (Pampliega, 1997; García Moreno, 1991, 61-277).

Tampoco podemos olvidar la presencia de elementos militares de origen bárbaro al servicio del Imperio y perfectamente integrados en el ejército romano (Palol, 1991, 279-282). Este hecho, precisamente, podría explicar la aparición de objetos de procedencia danubiana entre el 375 y el 450 (períodos D1 y D2 de Tejral) tanto en la Galia como en Hispania. Se trata de conjuntos de bárbaros originarios del danubio e instalados bajo el control de Roma como soldados (Kazanski, 1997, 286-287). Esto es particularmente válido para los objetos fechados en el período D3 (450/480-490) ya que no estamos en "período de grandes migraciones" en ese momento. Habría por lo tanto que hablar de pequeños conjuntos de bárbaros de origen danubiano al servicio de Roma primero y de los merovingios o de los visigodos a continuación (Kazanski, 1997, 296).

Es, precisamente, en este contexto previamente descrito, donde debemos ubicar la necrópolis tardorromana de Beiral (Ponte de Lima, Portugal) (Viana, 1961; Rigaud de Sousa, 1979, 293-303). Los materiales de esta necrópolis, que inicialmente fueron depositados en el Museo de Etnografía e História do Douro Litoral en Oporto, se encuentran actualmente una parte en el Museo Arqueológico de Lisboa, mientras que otra parte se halla en paradero desconocido, haciendo muy difícil, por no decir imposible, tener una visión coherente del conjunto de los hallazgos. Las noticias referidas por los que publicaron dicho material señalan que éste no se halló en las tumbas, de clara tipología tardorromana, sino en agujeros hechos en la tierra a modo de "depósitos funerarios". Las 20 sepulturas descubiertas son, como decimos, indudablemente tardorromanas, de forma trapezoidal hechas con teguale y orientadas. Entre los materiales destacan: un anillo de oro con decoración cloisonnée, compuesto por 17 piedras de color granate dispuestas radialmente alrededor de una central (Fig. 2b); un collar de oro (Fig. 2a), con paralelos en "tumbas principescas" de la primera mitad del siglo $\mathrm{V}$ d. C. El paralelo más cercano quizás sea el del collar hallado en una tumba femenina en Hochfelden

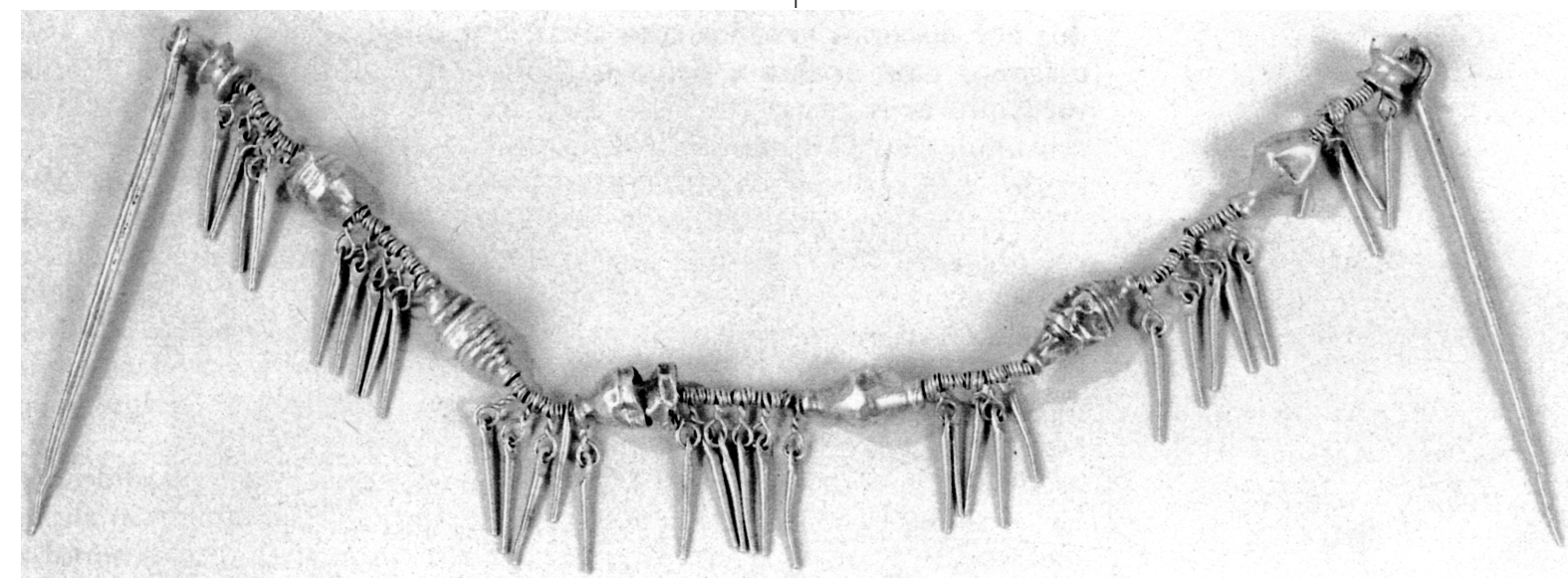

Figura 2 b.- Anillo de oro con decoración cloisinné hallado en la necrópolis de Beiral (Ponte de Lima, Portugal) (fotografía tomada de Ibid., 328). 


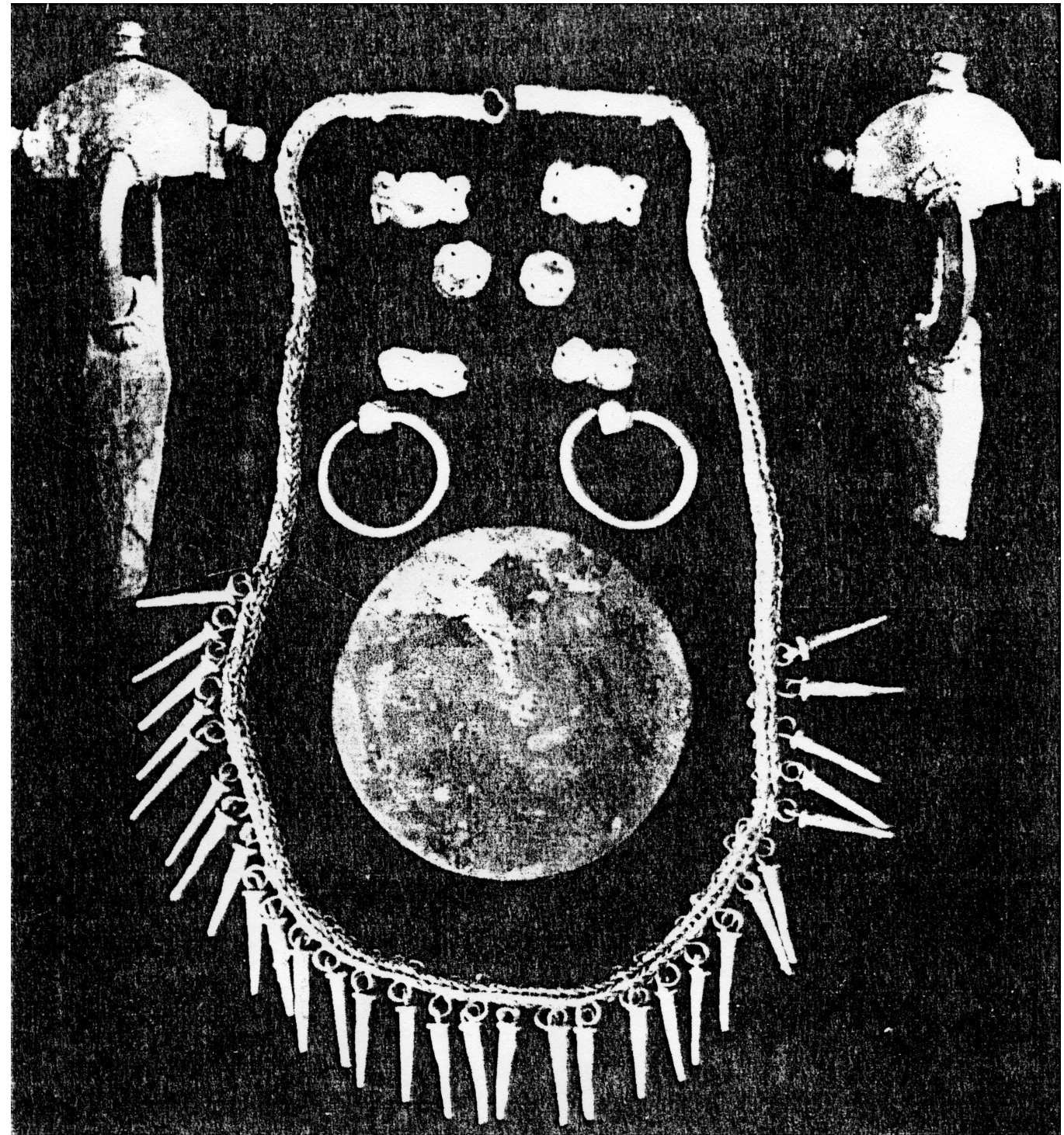

Figura 3.- Objetos hallados en la tumba femenina de Hochfelden: dos fibulas de plata, un collar de oro, dos pendientes de oro, un espejo y varias placas decorativas también de oro. $1^{a}{ }_{-}$del s. Vd. C. (tomado de: Hatt, J.J. "Une tombe barbare du Ve siècle ...", art .cit., 252).

(Departamento del Bajo-Rhin, Francia), a 30 $\mathrm{Km}$. de Estrasburgo y fechado a comienzos del siglo V d. C. (nivel D2 de Tejral (Hatt, 1965, 250256) (Fig. 3). Otros paralelos próximos los encontramos en Bakodpuszta (Hungría), fechado en el segundo tercio del siglo V d. C. (Goram, 1992, 41, no 31) (Fig. 4); en Kertsch, collar fechado por Bierbrauer alrededor del 400 (nivel D1 de Tejral) (Bierbrauer, 1991, 563, fig. 14, 4) (Fig. 5); además, por supuesto, del collar hallado en una tumba femenina de Untersiebenbrunn (Baja Austria), al lado de la ciudad romana de Carnuntum (capital de la Panonia I) y fechado en el primer tercio del siglo $\mathrm{V}$ d. C. (nivel D2 de Tejral) (Wieczoreck-Perin, 2001, 108-111).

En Beiral tenemos, por lo tanto, materiales que están en relación con lo que se conoce habitualmente como "horizonte Untersibenbrunn" o "horizonte Smolin o Kosino" para el centro de Europa. Es decir, el "nivel D2 (380/400-440/450) y D3 (430/40-470/480) de Tejral respectivamente. En efecto, el collar de Beiral es característico de la moda que encontramos entre finales del siglo IV y la primera mitad del V d. C. entre los miembros de la aristocracia bárbara proto-danubiana. Aristocracia con orígenes muy diversos y compuesta igualmente por una población muy heterogénea (Kazanski, 1989, 59-73) como la que llega a la Península Ibérica en el curso del siglo V d. C. (García Moreno, 1991, 87). Por lo tanto, en función de los paralelos y contexto, atribuimos el collar de Beiral al período D2 (380/400440/450) de la cronología de Tejral.

En Vigo (Pontevedra, España) se encontró en una tumba femenina de la necrópolis tardorromana, sita en la Rúa do Hospital de la mencionada 


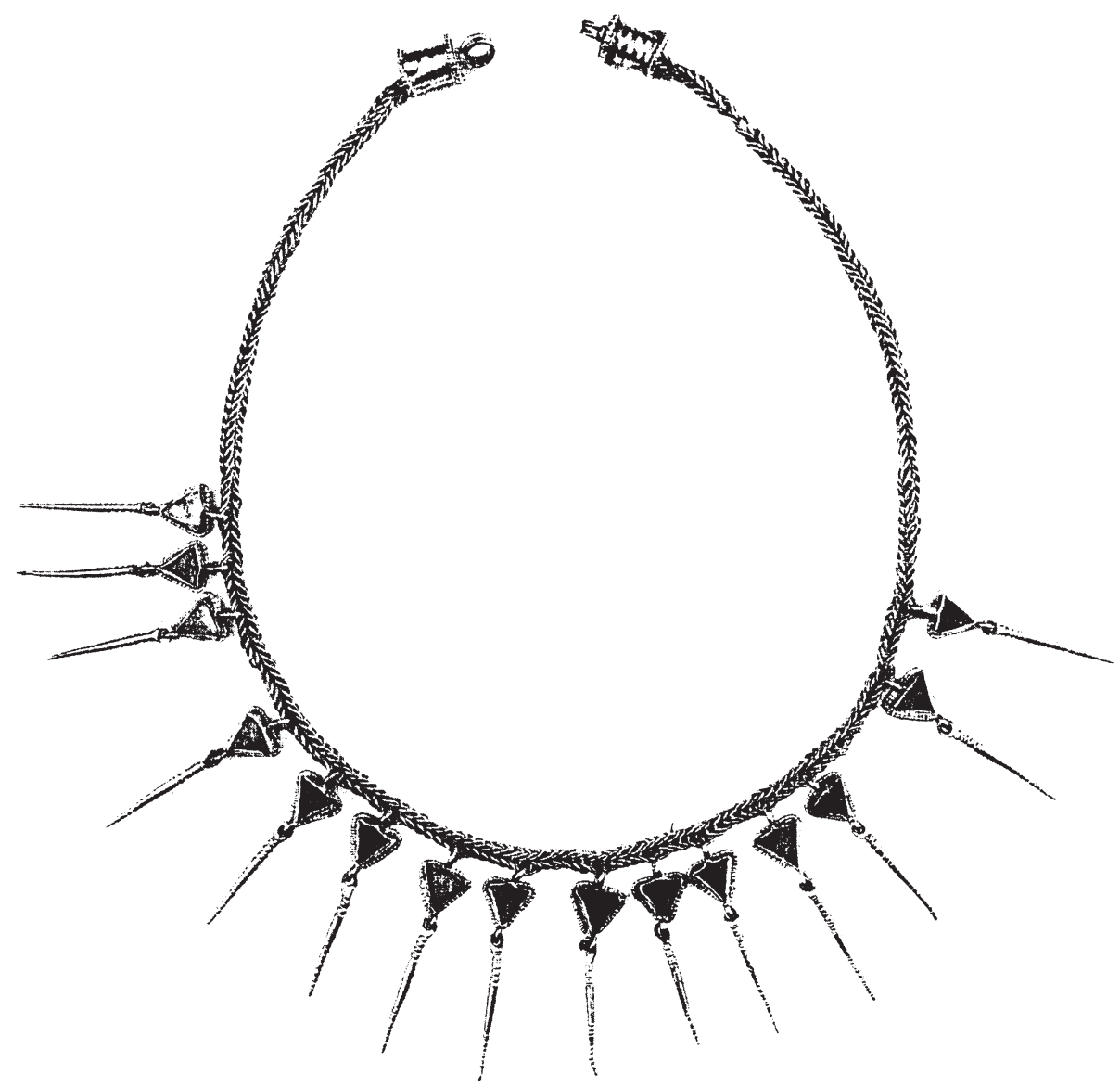

Figura 4.- Collar de oro hallado en Bakodpuszta. $2^{\circ} 1 / 3$ del siglo Vd. C. (tomado de Goram, E. - Kiss, A. Grabfunde aus der Völkerwanderungszeit ..., op. cit., 41, $\left.n^{\circ} 31\right)$.

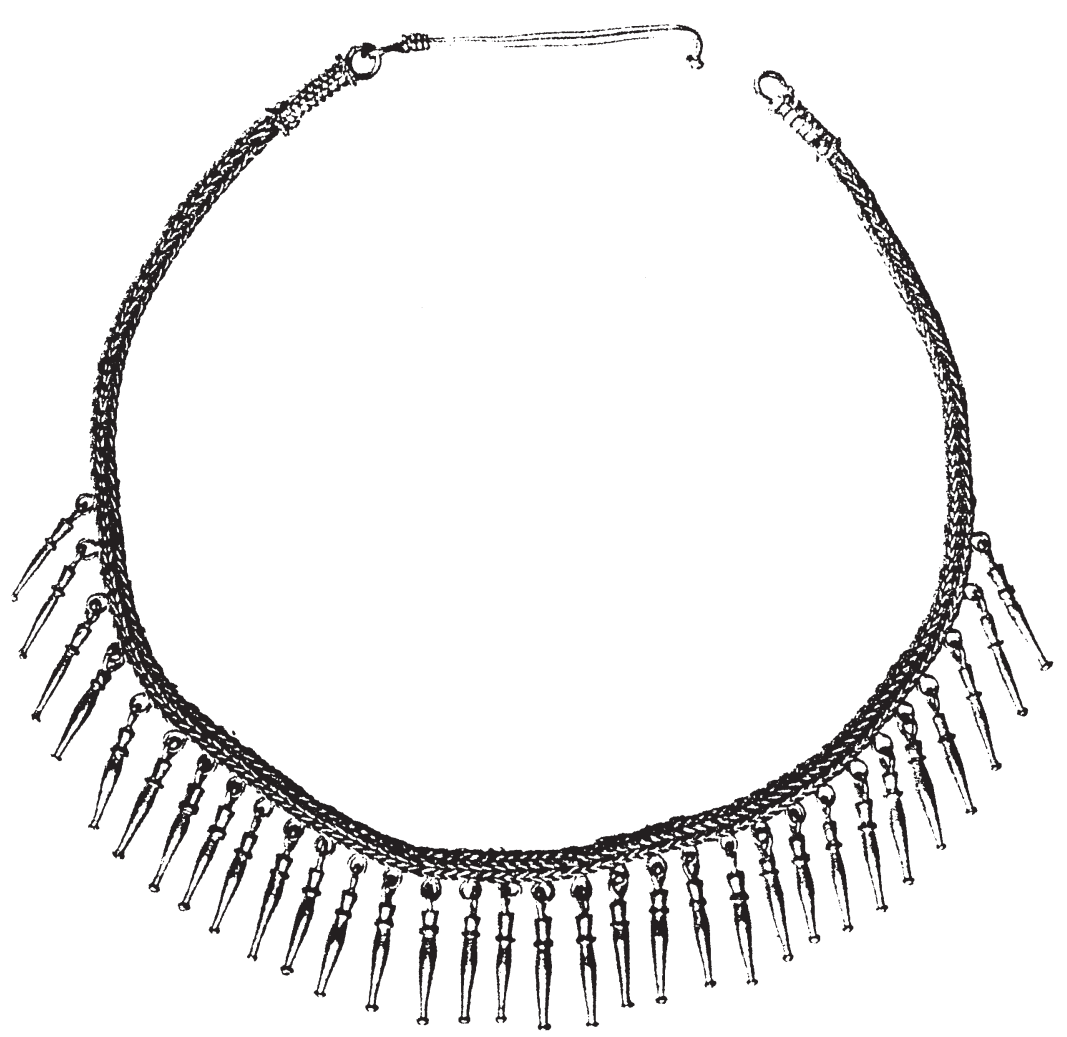

Figura 5.- Collar de oro hallado en Kertsch. Fechado hacia el 400, horizonte D1 de la cronología de Tejral (tomado de: Bierbrauer, V. "Das Frauengrab von Castelbolognese in der Romagna ...", art. cit., 563). 


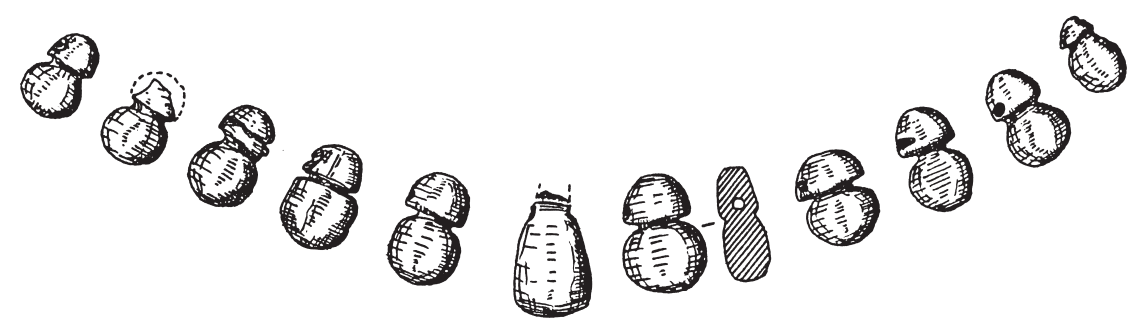

Figura 6 a.- Collar con perlas de ámbar en forma de champiñón hallado en Gundelsheim (Heilbronn, Alemania) (tomado de: Tempelmann-Maczynska, M. Die Perlen der römischen Kaiserzeit ..., op. cit., 82, abb. 13).

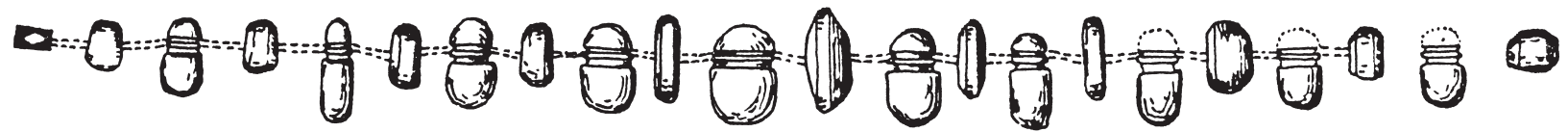

Figura 6 b.- Collar con perlas de ámbar en forma de champiñón hallado en Dienstedt (Arnstadt, Alemania) (tomado de: Tempelmann-Maczynska, M. Die Perlen der römischen Kaiserzeit ..., op. cit., 85, abb. 15b).

ciudad, un collar de perlas de ámbar en forma de champiñón (Casal García-Paz Lobeiras, 1997, 315322) (Fig. 9) o de "ocho" según la terminología empleada por Maczynska (TempelmannMaczynska, 1985, 81-86). Se trata, como en el caso del collar de Beiral, de un hallazgo único y sin paralelo en el conjunto de la Península y que normalmente es considerado como un fósil director para los contextos en los que se encuentra (Tempelmann-Maczynska, 1985, 81-86). En el caso de la necrópolis de Vigo, el contexto es igualmente tardorromano, puesto que nos hallamos ante sepulturas prismático-triangulares y materiales claramente romanos (Hidalgo Cuñarro-Viñas Cue, 1998, 807-839), algo que es común a todos los lugares donde aparecen este tipo de collares (Tempelmann-Maczynska, 1985, 85-86).

Cronológicamente podemos situar este tipo de perlas en el nivel C1 (160/180-260/270), en el C2 (260/270-300/310) o a lo más en el nivel D, es decir, a finales del siglo IV o a principios del V d. C. (Tempelmann-Maczynska, 1985, 85-86). Encontramos suficientes paralelos que apuntan a esta cronología como la más característica para los collares con perlas de ámbar en forma de champiñón:

- En la tumba infantil n ${ }^{\circ}$ 90-91 de la necrópolis tardorromana de Szentendre (en Panonia, Hungría), fechada entre finales del siglo III y finales del IV d. C. (Maroti - Topal, 1980, 79-177, fig. 26) (Fig. 8, 3).

- En la necrópolis de Gundelsheim (Heilbronn, Alemania) ((Tempelmann-Maczynska, 1985, 82, fig. 13) (Fig. 6, 1).

- En Diensted (Arnstadt, Alemania) ((Tempelmann-Maczynska, 1985, 85, fig. 15b) (Fig. 6, 2).

- En Ruzicanka (Chmelnickij), collar hallado en la tumba $\mathrm{n}^{0} 55$ de esta necrópolis (Maczysnka, 1997, 111, fig. 5) (Fig. 8,1).

- En una tumba de Colonia (Alemania) (Ka- zanski, 1990/91, 112, fig. 2, nº2) (Fig. 8, 2).

- En la tumba $n^{0} 16$ de Gródel mam Burg (Kazanski, 1992, 127, fig. 10) (Fig. 8,4).

- En Wildschütz (Hohenmölsen, Alemania) ((Tempelmann-Maczynska, 1985, 83, fig. 14) (Fig. 7, 1).

- En una tumba femenina de la necrópolis de Vermand (Picardía, Francia) (Kazanski, 1990/91, 112, fig., 2, no3) (Fig. 7, 2).

Un paralelo especialmente interesante es el correspondiente a la tumba $\mathrm{n}^{\mathrm{O}} 12$ de la necrópolis suburbana de Hürth-Hermülheim (Colonia, Alemania) (Fig. 6, 3) (Gottschalk, 1999, 84, fig. 3). Se trata de una necrópolis formada por 17 tumbas ubicadas al lado de la vía romana que unía Colonia y Treveris, a 7'5 Km. del centro del actual núcleo urbano. En la tumba $n^{\circ} 12$ de esta necrópolis, que pertenecía a una mujer de unos $4^{\mathrm{O}}$ o 50 años, se hallaron recipientes de vidrio (vasos tipo Gellep 191 y tipo Trier 53) fechados en la segunda mitad y finales del siglo IV d. C. y, entre otras perlas de vidrio, se encontraron nueve de ámbar en forma de champiñón o de ocho. La presencia de estas perlas plantea el problema de la identidad de esta mujer: ċromana o 'germánica'? ¿Estas perlas han sido importadas por una mujer de origen romano o aportadas por una

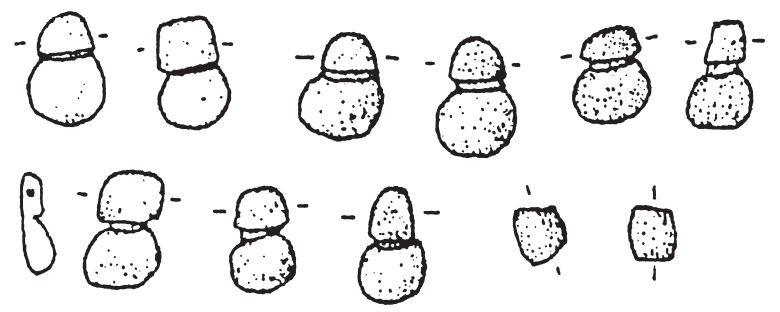

Figura 6 c.- Collar con perlas de ámbar en forma de champiñón hallado en la tumba $n^{0} 12$ de Hürth-Hermülheim (Colonia, Alemania) (tomado de: Gottschalk, R. "Zur ethnischen Einordnung einiger spätantiker Gräber des Rheinlandes”..., art. cit., 84, abb 3). 


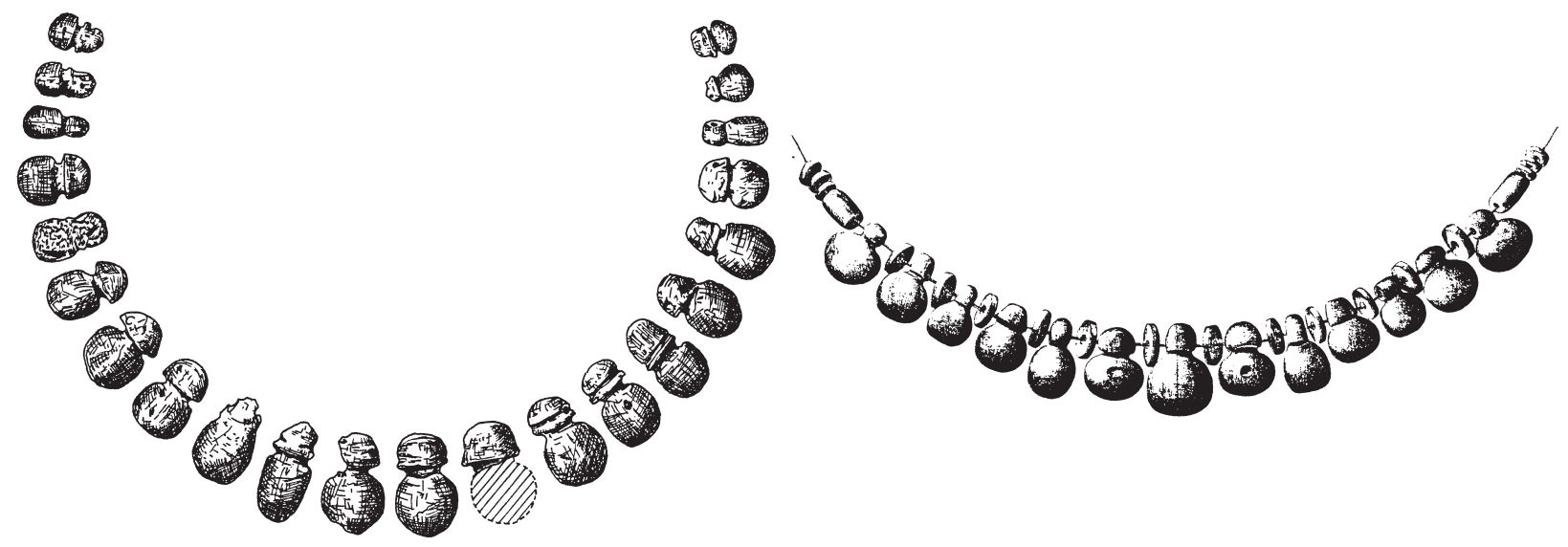

Figura 7 a.- Collar con perlas de ámbar en forma de champiñón Figura 7 b.- Collar con perlas de ámbar en forma de champiñón hallahallado en Wildschütz (Hohenmölsen, Alemania) (tomado de: Tempelmann-Maczynska, M. Die Perlen der römischen Kaiserzeit ..., op. cit., 83, abb. 14).

do en una tumba femenina de la necrópolis de Vermand (Picardía, Francia) (tomado de Kazanski, M. "Les Germains de l'Elbe-OderVistule et la Gaule au Bas-Empire...”, art. cit., 112, fig. 2, n³).

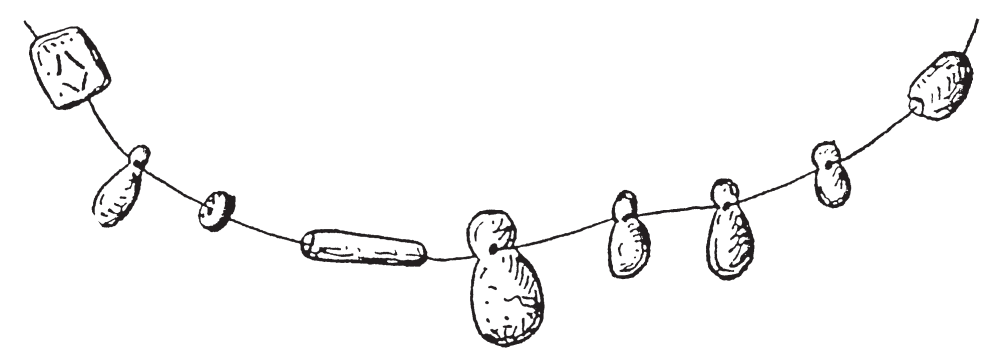

Figura 8 a.- Collar con perlas de ámbar en forma de champiñón hallado en la tumba $n^{0} 55$ de la necrópolis de Ruzicanka (Chmelnickij) (tomado de: Maczynska, M. "Die 'barbarische' Kette der Römischen Kaiserzeit...", art. cit., 111, abb. 5).

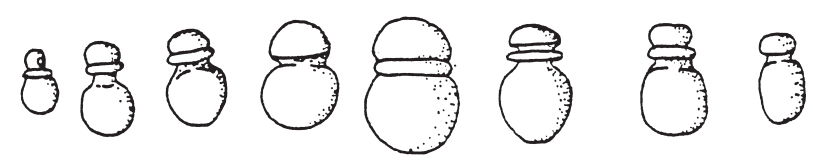

Figura 8 b.- Collar con perlas de ámbar en forma de champiñón hallado en una tumba en Colonia (Alemania) (tomado de: Kazanski, M. "Les Germains de l'Elbe-Oder-Vistule...", art. cit., 112, fig. 2, $n^{0} 2$ ).

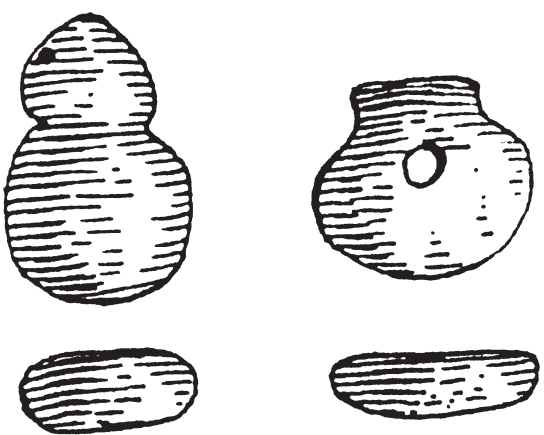

Figura 8 c.- Collar con perlas de ámbar en forma de champiñón hallado en las tumbas no 90 y 91 de la necrópolis de Szentendre (tomado de Tejral, J. "Zur chronologie der frühen Völkerwanderungszeit ...”, art. cit., 236, abb. 8).

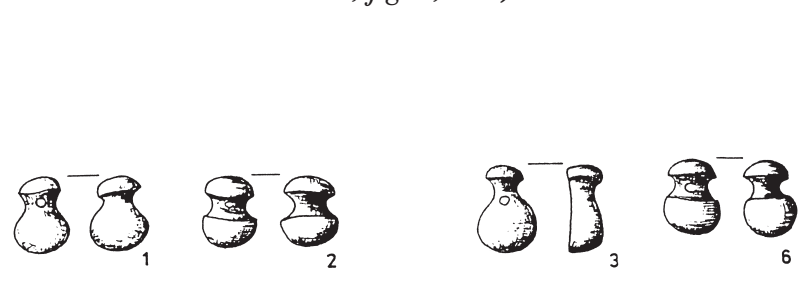

Figura 8 d.- Collar con perlas de ámbar en forma de champiñón hallado en la tumba $n^{0} 16$ de Gródek am Burg (tomado de

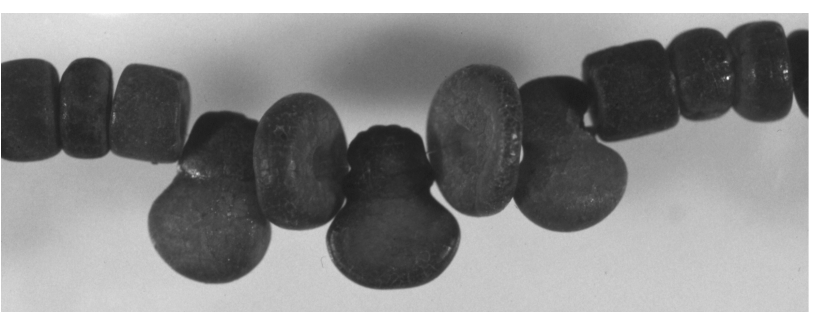
Kokoweski, A. "Das Problem der Wiederöffnung der Gräber...", art.

Figura 9.- Collar con perlas de ámbar en forma de champiñón hallado en una tumba femenina en la necrópolis de la Rúa Hospital (Vigo, Pontevedra) (fotocit., 127, abb. 10). Historia I, Universidad de Santiago de Compostela). 
mujer de origen 'germánico'? (Gottschalk, 1999, 85). Para esta necrópolis de Hürth-Hermülheim se habla también de la posibilidad de que se trate de una mujer de origen 'germánico' integrada en un grupo de población de origen local provincial - romano (Gottschalk, 1999, 85). ¿Podría ser también este el caso de la tumba femenina hallada en la necrópolis de Vigo? En el estado actual de la investigación y de nuestros conocimientos esto no es más que una hipótesis de trabajo.

Normalmente, este tipo de perlas de ámbar en forma de champiñón son características de tumbas femeninas de 'germanos' occidentales y de los denominados 'germanos del Elba', concretamente de las regiones centrales y orientales de la Germania Libera (Kazanski, 1990/91, 113). Maczysnka subraya que este tipo de perlas que encontramos habitualmente en el ámbito de la conocida como 'cultura de Cernjachov' son piezas muy importantes en la región del este de Pomerania, es decir, de áreas geográficas que se corresponden con la 'cultura de Wielbark' y del denominado 'grupo Maslomecz'. Subraya Maczynska además que este tipo de perlas son mucho más frecuentes de lo que normalmente se piensa dentro de la 'cultura de Cernjachov' (Maczynska, 1997, 104). Probablemente estos tres grupos culturales (Cernjachov, Wielbark y Maslomecz) han debido de participar en un importante comercio de este tipo de perlas provenientes tanto del Norte como del Sureste durante el período C para esos ámbitos geográficos (finales del siglo II a comienzos del IV d. C. (Maczynska, 1997, 105).

El collar de Vigo puede ser considerado actualmente como el hallazgo más occidental de este tipo de perlas de ámbar en forma de champiñón para el conjunto de Europa. Tanto por su cronología (finales del IV o comienzos del siglo $\mathrm{V}$ d. C.) como por su contexto claramente tardorromano, la tumba femenina de Vigo plantea el problema de la interpretación de este tipo de piezas "foráneas" halladas, tanto en la Gallia como en la Península Ibérica, en contextos claramente dominados por la población local tardorromana durante el conocido como período de las Grandes Migraciones en Occidente. ¿La mujer de Vigo ha importado su collar o lo ha traído consigo desde el centro de Europa (región del Danubio) hasta Galicia? A esta pregunta nos es imposible responder por el momento.

Ambos hallazgos, el de Beiral y el de Vigo,

1. Se trata de una fíbula de bronce (en un estado muy fragmentario de conservación) fechada en el siglo V d. C., sin más precisiones. Esta fíbula se halló en las excavaciones del campamento militar tardorromano de Cidadela. Su tipología, sin paralelo exacto conocido, es muy similar a la de ciertas fíbulas de arco características del Danubio plantean además la cuestión problemática de la hipotética identificación 'étnica' de estos materiales (Brather, 2000, 139-177). Es muy difícil, por no decir que prácticamente imposible, el tratar de vincular estos hallazgos con alguno de los grupos 'germánicos' que llegan a la Península a comienzos del siglo V d. C. (Suevos, Vándalos o Alanos), ni por su contexto, como decimos claramente tardorromano, ni por su tipología.

En lo que respecta a la necrópolis de Beiral, se podría plantear una relación con grupos de Vándalos, como acontecería con otros hallazgos del siglo $\mathrm{V}$ d. C. en la Península Ibérica (en Coimbra, en Beja o en Granada - Albaicín) (König, 1981, 299-360; Kazanski, 2000, 189-202; Ibid., 1991, 123-139; Raddatz, 1959, 142-150; Tempelmann-Maczynska,1986, 375-387) o en el Norte de África (Eger, 2001, 347-390), ello sin excluir totalmente la opción de una hipotética relación con grupos suevos (Kazanski, 2000, 189202), especialmente si tenemos en cuenta la heterogénea composición de este conglomerado de 'germanos' occidentales (Pampliega, 1997; García Moreno, 1991), y sin olvidar a los Alano Sármatas. En todo caso, no podemos excluir la hipótesis de la presencia en Beiral de una tumba dejada por la esposa de un jefe militar 'bárbaro' al servicio probablemente del Imperio romano. Esta mujer habría sido inhumada en costume princier de tipo danubiano, aunque sin las dos fíbulas características sobre la espalda representativas de la conocida como 'moda danubiana' (por ejemplo, en la tumba de Airan o en la de Hochfelden). Precisamente, la ausencia de estas fíbulas sobre la espalda impide emitir una opinión más concisa sobre la identidad de la difunta.

En el caso de la necrópolis de Vigo, no estamos realmente seguros de que el collar de perlas de ámbar en forma de champiñón haya pertenecido a una mujer romana de origen local o que pueda haber sido el adorno de una mujer de origen 'germánico', puesto que tanto la cronología como el contexto tardorromano así como la ausencia de fíbulas o de otro tipo de materiales más característicos, permiten emitir todo tipo de hipótesis. De todas formas, resulta evidente que los hallazgos de Beiral, los de Vigo, así como los de Coimbra (Schulze-Dörrlamm, 1986; Kazanski, 2000), Falperra (Braga) (Rigaud de Sousa, 196667, 143-150; Schlunk, 1971, 475-509), Cidadela (Sobrado dos Monxes, A Coruña) (Caamaño Gesto, 1984, 233-254)(1), Baamorto (Lugo) (Koch,

medio. Quizás podría aproximarse la fíbula de Cidadela a las de tipo "Bratei", de origen germánico-oriental y que se encuentran en el Danubio medio y en Crimea, fechadas en el período D2/D3. ¿Se trataría, una vez más, de un soldado 'bárbaro' al servicio del ejército imperial? 
1999, 1999, 156-198, fig. 2)(2), Mérida (Kazanski, 2000, 201, fig. 4) ${ }^{(3)}$, Beja (Alentejo, Portugal) (Kazanski, 1991, 123-139; Raddatz, 1959, 142150; Kazanski, 1996, 118-122)(4), Granada Albaicín (Tempelmann-Maczynska, 1986, 375387), así como algunos tipos de fíbulas consideradas como 'visigodas' y halladas en el centro de la Península (Ebel-Zepezauer, 1994, 380-397; Bierbrauer, 1994, 51-172), permitirían, en nuestra opinión, halar de un "nivel I" para el siglo V d. C. en la Península Ibérica.

Sería, por lo tanto, necesario, como ya fue señalado por Bierbrauer (Bierbrauer, 1994), revisar cuidadosa y meticulosamente todos los materiales fechados en el siglo $\mathrm{V}$ d. C. de la Península Ibérica, algunos de ellos demasiado sistemáticamente atribuidos a 'visigodos', como en particular ciertas fíbulas de cabeza semicircular y pie alargado (tipo "Smolin" y "Kosino-Gyuilavan) o incluso algunas placas de cinturón de mediados o de la segunda mitad del siglo $\mathrm{V} \mathrm{d}$. C. con paralelos muy claros en la Europa central danubiana (Kazanski, 1991). A ellos habría que añadir los materiales hallados en el noroeste y oeste de la Península. Particularmente significativo nos parece, en este sentido, el conjunto de fíbulas halladas en diferentes lugares de Portugal que Salete da Ponte clasifica como "fíbulas romanas tardías", concretamente las de tipo en "P", que considera en claro contexto de 'tropas germánicas' al servicio de Roma (Salete da Ponte, 2001, 456-457)(5).

La imagen que así obtendríamos nos mostraría, con toda probabilidad, la gran heterogeneidad poblacional que caracteriza la Hispania del siglo V d. C., pero sobre todo resaltaría la homogeneidad del ámbito cultural del que provienen la mayoría sino la totalidad de estos objetos "foráneos" hallados en la Península Ibérica: la cuenca central del Danubio.

\section{REFERENCIAS BIBLIOGRÁFICAS:}

Bierbrauer, V. 1991: "Das Frauengrab von Castelbo-lognese in der Romagna (Italien)_Zur chronologischen,

2. La argumentación de Koch es difícil de seguir en lo que se refiere a la atribución a los 'Suevos' de este broche de cinturón de Baamorto.

3. Se trata de la fíbula de la villa romana de El Hinojal/ Las Tiendas, sita en la provincia de Badajoz.

4. El lugar de Beja se ubica en la línea de defensa marítima creada contra los piratas Sajones y Hérulos (mencionados por Hidacio en su crónica en las costas de Galicia y de Portugal). Según Kazanski, con el que coincidimos plenamente, este tipo de tumbas como la de Beja habrían sido dejadas por 'bárbaros' orientales ('Germanos', Alano-Sármatas o Hunos) al servicio del Imperio romano. Se trataría de 'jefes militares' enterrados con sus espadas (como en Altlussheim, Wolfsheim o Mundolsheim) (Kazanski, 1996, pp. 118-122). ethnischen und historischen Auswertbarkeit des ostgermanischen Fundstoffs des 5. Jahrhunderts in Südosteuropa und Italien", Jahrbuch des RömischGermanisch Zentralmuseum Mainz 38, 563 (Abb. 14, 4).

Bierbrauer , V.1994: "Archäologie und Geschichte der Goten vom 1.-7 Jahrhundert", Frühmittelalterliche Studien 28, 51-172.

Brather, S. 2000: "Ethnische Identitäten als Konstrukte der frühgeschichtlichen Archäologie", Germania 78, 139-177.

CAAmaño Gesto; J. M. 1984: "Excavaciones en el campamento romano de Cidadela (Sobrado dos Monxes, A Coruña)", Noticiario Arqueológico Hispánico 18, 233-254.

Casal García, R. - Paz Lobeiras, R. 1997: "Un collar de ámbar suévico en Vigo”, Gallaecia 16, 315-322.

Ebel-ZepezAuer, W. 1994: "Frühe gotische Blechfibeln in Spanien”, Madrider Mitteilungen 35, 380-397.

EgER, Ch. 2001: "Vandalische Grabfunde aus Karthago", Germania 79, 347-390.

García Moreno, L. A. 1991: "Las invasiones, la ocupación de la Península", in: Historia de España ( $R$. Menéndez Pidal), vol. III, Madrid, 61-277.

Goram, E. - KISS, A. 1992: Goldfunde aus der Völkerwanderungszeit im Ungarischen Nationalmuseum, Budapest.

GotTschalK, R. 1999: "Zur ethnischen Einordnung einiger spätantike Gräber des Rheinlandes", in: $T$. Fischer-Gundolf Precht-J. Tejral (Hrsg.), Germanen beiderseits des spätantiken Limes, Köln-Brno, 1999, 84 ss.

HATт, J. - J. 1965: "Une tombe barbare du Ve siècle à Hochfelden (Bas-Rhin)", Gallia XXIII, 250-256.

Hidalgo Cuñarro, J. M. - Viñas Cue, R. 1998: "El Vigo romano y su problemática", in: Los orígenes de la ciudad en el noroeste hispánico (A. Rodríguez Colmenero), Lugo, 807-839.

KAZANSKI, M. 1989: "La diffusion de la mode danubienne en Gaule (fin du IVe siècle-début du VIe siècle): essaie d'interprétation historique", Antiquités Nationales 21, 59-73.

5. Nos referimos a las fíbulas halladas en la ciudad romana de Conimbriga y conservadas en el museo del mismo nombre (no. 288, 290, 291, 293, 294, 295, 296, 297 y 325, del catálogo de Salete da Ponte, 2001); la de Vitória do Ameixal (Estremoz), en el Museo Nacional de Arqueología ( ${ }^{\circ}$ 289, Salete da Ponte, 2001); la de Idanha-a-Velha (Castelo Branco), conservada en la sede de la parroquia de Idanhaa-Velha ( ${ }^{\circ}$ 292, Salete da Ponte, 2001); la de Monte Moxzinho (Codeixa-a-Nova), en el Museo de Conimbriga (no 298, Salete da Ponte, 2001); la del Castro de Falperra (Braga), ya mencionada, en el Museo D. Diego de Sousa en la misma ciudad ( $n^{\circ} 299$, Salete da Ponte, 2001); y la de la Cerca do Castelo de Sines, en el Museo del Arch. Municipal de Sines (n³00, Salete da Ponte, 2001). 
KAZANSKI , M. 1990/91: "Les Germains de l'Elbe-OderVistule et la Gaule au Bas-Empire”, Antiquités Nationales 22/23, 112 ss.

KAZANSKi , M. 1991: "À propos des armes et des éléments de harnachement "orientaux" en Occident à l'époque des Grandes Migrations (IVe-Ve s.)", Journal of Roman Archaeology 4, 123-139.

KazAnski , M. 1991: Les Goths (Ier.VIIe après J. C.), París.

KAZANSKI , M. 1996: "Les Sarmates et les Alains dans l'Occident romain", in: L'or des Sarmates. Nomades des steppes dans l'Antiquité (catalogue d'expossition), Abbaye de Daoulas.

KazAnski , M. 1997: "La Gaule et le Danube à l'époque des Grandes Migrations", in: Neue Beiträge zur Erforschung der Spätantike im mittleren Donauraum, Brno, 286-287.

KAZANSKI , M. 2000: "Les fibules originaires de l'Europe Centrale et orientale trouvées dans les Pyrenées et en Afrique du Nord. À propos des traces archéologiques des Suèbes, des Vandales et des Goths dans la Mediterranée occidentale à l'époque des Grandes Migrations”, in: Superiores Barbari, Kraków, 89-202.

Koch, A. 1999: "Zum archäologischen Nachweis der Sueben auf der Iberischen Halbinsel. Überlegungen zu einer Gürtelschnalle aus der Umgebung von Baamorto/Monforte de Lemos (Prov. Lugo, Spanien)", Acta Praehistorica et Archaeologica 31, 156-198.

KoKowski, A. 1992: "Das problem der Wiedereröffnung der Gräber in den Friedhofen der MaslomeczGruppe (aus den Studien über die Kulturveränderungen bei den Gotten während ihrer Wanderung)", in: E. Straume- E. Skar (dir.), Peregrinatio Gothica III, Oslo, 1992, 127 (Abb. 10).

KÖNIG, G. 1980: "Archäologische Zeugnisse westgotischer präsenz im 5. Jahrhundert”, Madrider Mitteilungen 21, 220-247.

KÖNIG , G. 1981: "Wandalische Grabfunde des 5. Und 6. Jahrhunderts”, MadriderMitteilungen 22, 299-360.

Maroti, E. - Topal, J. 1980: "Das römerzeitliche Gräberfeld von Szentendre", Studia Comitatensia 9, 79-177.

MaCZYNSKA, M. 1997: “Die 'barbarische' Kette der Römischen Kaiserzeit- ihre Zusammensetzung am Beispiel der Cernjachov-Kultur”, in: U. Von FreedenA. Wieczorek (Hrsg.), Perlen. Archäologie, Techniken, Analysen, Bonn, 11 (Abb. 5).

Palol, P. 1991: "Arte y Arqueología", in: Historia de España (R. Menéndez Pidal), III. 2, España Visigoda. La Monarquía, la cultura, las artes, Madrid, 279-282.

Pampliega, J. 1997, Los germanos en España, Pamplona.

RADDATZ，K. 1959: "Das Völkerwanderungszeitliche
Kriegergrab von Beja, Südportugal”, Jahrbuch des Römisch-Germanisch Zentralmuseum Mainz 6, 142-150.

Rigaud DE SousA, J.J. 1966-67: "A estaçâo Arqueologica de Falperra. Notas para a sua História", Arquivo de Beja XXIII-XXIV,143-150.

RigAUd DE SOUSA, J.J. 1979: "Novas consideraçôes sobre a necropole do Beiral (Ponte de Lima)", Gallaecia 5, 293-303.

RIPOLL, G. 1991: "Materiales funerarios de la Hispania visigoda: Problemas de cronología y tipología”, in: Gallo-romains, Wisigoths et Francs en Aquitaine, Septimanie et Espagne (Actes des VIIe Journées internationales d'Archéologie mérovingienne, Toulouse 1985), Rouen, 111-132.

Sasse, B. 1997: "Die Westgoten in Südfrankreich und Spanien. Zum Problem der archäologischen Identifikation einer wandernden 'gens'", Archäologische Informationen 20/1, 29-48.

SCHLunk, H. 1971: "Die frühchristlichen Denkmaler aus dem Nord-Westen der Iberischen Halbinsel", Legio VII. Gemina, León, 475-509.

SChulze-Dörrlamm, M. 1986: "Romanisch oder Germanisch? Untersuchungen zu den Armbrustund Bügelknopffibeln des 5. Und 6. Jahrhunderts n. Chr. Aus den gebieten westlich des Rheins und Südlich der Donau", Jahrbuch des Römisch-Germanisch Zentranmuseum Mainz 33, 593-723.

TejRal, J. 1988: "Zur Chronologie der frühen Völkerwanderungszeit im mittleren Donauraum", Archaeologia Austriaca 72, 223-304.

TejRAL, J. 1997: "Neue Aspekte der frühvölkerwanderungszeitlichen Chronologie im Mitteldonauraum", in: M. Kazanski-J. Tejaral (Hrsg.), Neue Beiträge zur Erforschung der Spätantike im mittleren Donauraum, Brno, 321-392.

TEJRAL, J. 1999: “Archäologisch-kulturelle Entwicklung im norddanubischen Raum am Ende der Spätkaiserzeit und am Anfang der Völkerwanderungszeit", in: J. Tejral. Ch. Pilet-M-Kazanski (Hrsg), L'Occident romain et l'Europe centrale au debut de l'époque des Grandes Migrations, Brno, 205-271.

Tempelmann-Maczynska, M. 1985: Die Perlen der römischen Kaiserzeit und der frühen Phase der Völkerwanderungszeit im mitteleuropäischen Barbaricum, Mainz.

Tempelmann-Maczynska, M. 1986: "Der Goldfund aus dem 5. Jahrhundert n. Chr. Aus Granada-Albaicín und seine beziehungen zu Mittel-und Osteuropa", Madrider Mitteilungen 27, 375-387 (Taf. 73-77).

Wieczoreck, A. - Perin, P. 2001: Das Gold der Barbarenfürsten. Schätze aus Prunkgräbern des 5. Jahrhunderts $n$. Chr. Zwischen Kaukasus und Gallien, Stuttgart, 108-111. 